\title{
Language abilities in preschool-aged siblings of children with autism spectrum disorders - preliminary report
}

\section{BACKGROUND}

The characteristics of autism spectrum disorders (ASD) observed among relatives of people affected with autism are referred to as broader autism phenotype (BAP). Among the components of BAP are language and communication skills. Research to date on these skills amongst the relatives of individuals with ASD is inconclusive. Furthermore, limited data are available about preschool-aged siblings of children with ASD.

\section{PARTICIPANTS AND PROCEDURE}

Eighty-six children aged 4 years and 6 months -6 years and 11 months took part in the study (32 girls and 54 boys). They were divided into four groups: siblings of children with autism (S/ASD), high-functioning children diagnosed with autism spectrum disorders (HF/ASD), siblings of children with Down syndrome (S/DS) and siblings of typically developing children (Controls, C). Communication and language skills were tested using the Vocabulary Test for Children (TSD). It was used to assess two kinds of verbal skills: receptive language (passive) and expressive language (active).

\section{RESULTS}

No differences were observed in expressive lanquage or receptive language between siblings of children with ASD and siblings of children with DS as well as typically developing children. In terms of receptive language and general communication skills, siblings of children with ASD scored higher than high functioning children with ASD. High functioning children with ASD displayed difficulties with receptive language, expressive language, general language and communication skills.

\section{CONCLUSIONS}

The results suggest that siblings of children with ASD do not display deficits in communication and language skills. It is however important to note that due to a small sample size this study should be considered as preliminary.

\section{KEY WORDS}

autism spectrum disorders; siblings; pre-schoolers; language and communication abilities

ORganizations - Faculty of Psychology, University of Warsaw, Warsaw, Poland

AUthors' Contribution - A: Study design - B: Data collection - C: Statistical analysis - D: Data interpretation .

E: Manuscript preparation · F: Literature search · G: Funds collection

Corresponding Author - Prof. Ewa Pisula, Faculty of Psychology, University of Warsaw, 5/7 Stawki Str.,

00-183 Warsaw, Poland, e-mail: ewa.pisula@psych.uw.edu.pl

to Cite this ARTICLE - Pisula, E., Ziegart-Sadowska, K., \& Kawa, M. (2015). Language abilities in preschool-aged siblings of children with autism spectrum disorders - preliminary report. Health Psychology Report, 3(3), 179-190.

DOI: $10.5114 /$ hpr.2015.48306 


\section{BACKGROUND}

Autism spectrum disorders (ASD) are a group of neurodevelopmental disorders characterised impairments communication and restricted patterns of behaviours, interests and activities (American Psychiatric Association, 2013; World Health Organization, 2002). Their aetiology is not known, though it is now believed that both environmental and genetic factors play a crucial role (Currenti, 2010; Dodds et al., 2011).

Ewa Pisula, Karolina Ziegart-Sadowska, Magdalena Kawa

Amongst the arguments for the genetic background of ASD are the results of studies on broader autism phenotype (BAP) among the closest relatives of individuals affected with ASD, i.e. their parents and siblings. Broader autism phenotype is defined as a set of specific social and communication skills as well as personality features, considered to be a 'lighter' expression of features characteristic for autism (Cruz et al., 2013; Sucksmith, Roth, \& Hoekstra, 2011). It is important to note that BAP does not constitute a separate diagnostic entity - difficulties observed in families of individuals with ASD are too mild to fulfil the criteria needed to be defined as a disorder (Gerdts \& Bernier, 2011).

Characteristics typical of BAP are observed in at least $10 \%$ of brothers and sisters of people with ASD (Landa \& Garret-Mayer, 2006). Bolton and his co-workers (1994) determined their presence in about $12.40 \%$ of individuals from that group and only in $1.60 \%$ of siblings of people with Down syndrome (DS). In their systematic literature review, Cruz et al. (2013) concluded that BAP occurs in $12-30 \%$ of siblings of individuals with ASD. Most studies indicate that at least half of the relatives of people with ASD do not show any deficits in the analysed areas, which suggests that features associated with BAP occur in a subgroup of the family members (Gerdts \& Bernier, 2011).

The set of characteristics comprising BAP has not been precisely defined. Dawson et al. (2002) include difficulties in face processing (associated with recognising emotions), problems with social affiliation or sensitivity to social reward, difficulties in motor imitation ability (especially body movements), less developed memory skills, especially those associated with the activity of temporoprefrontal pathways (i.e. processing social stimuli), impairments in executive functions (planning and flexibility of action) and reduced language abilities. Sucksmith et al. (2011) proposed a division of the characteristics observed among the relatives into three main groups - related to three levels of functioning: (1) behavioural level - communication and language abilities, social interactions and repetitive, stereotypical behaviours and interests; (2) cognitive level - the theory of mind, executive functions, visual attention, sensory integration and central coher- ence, language abilities in the area of phonological processing, reading and automatized naming, motion perception and sensitivity to contrasts as well as general cognitive abilities, as measured by IQ tests; (3) personality features - rigidity, impulsiveness and aloofness.

It follows from the presented information that language and communication abilities are relevant areas of BAP. Difficulties in communication are an important part of ASD. Their degree and intensity vary among people with ASD. They may apply to both verbal and non-verbal communication, understanding and expression (Tager-Flusberg, Paul, \& Lord, 2005). Therefore an attempt to verify whether similar difficulties also occur among the relatives of individuals with autism (being a part of BAP) seems justified. Previous results suggest that a delayed or atypical course of language development occurs in about $20 \%$ of siblings of individuals with ASD (Chuthapisith, Ruangdaraganon, Sombuntham, \& Roongpraiwan, 2007; Constantino et al., 2010).

Research on language and communication abilities in relatives of people with ASD can be divided into two groups: the recently very popular studies on communication abilities in infants and toddlers, and research on older siblings and parents (especially fathers). A large number of studies with infants from the high-risk (HR) group, i.e. having older siblings diagnosed with ASD, aim at defining the early behavioural and developmental characteristics that allow differentiation of children at risk of developing autism from those developing typically or with other kinds of developmental difficulties. When interpreting the results of these studies, one needs to note that some of the subjects will be diagnosed with ASD in the future. This may lead to an overestimation of BAP frequency in the investigated group, as some of the observed developmental characteristics will be recognized as an early expression of symptoms of ASD.

Studies on early development of communication and language abilities among HR infants and toddlers suggest delays in linguistic development (Iverson \& Wozniak, 2007), less developed receptive skills and poorer language expression (Landa \& Garrett Mayer, 2006; Toth, Dawson, Meltzoff, Greenson, \& Fein, 2007; Yirmiya et al., 2006; Zwaigenbaum et al., 2005), less behavioural requesting (Cassel et al., 2007; Goldberg et al., 2005), poorer understanding of words and phrases, and a less frequent use of gestures (Mitchell et al., 2006; Zwaigenbaum et al., 2005), as well as a less developed ability to communicate during interactions with parents (Stone, McMahon, Yoder, \& Walden, 2007). It has been shown that HR children aged 18-27 months used fewer words and gestures and smiled less frequently than children from the control group (Toth et al., 2007). Goldberg et al. (2005) found a difference between 14-19-monthold HR children and children from the control group 
on three subscales of the Early Social Communication Scales (ESCS, Mundy, Hogan, \& Doehring, 1996): Responds to Social Interaction, Initiates foint Attention and Requesting Behaviours. Impairments in the development of both expressive and receptive language abilities among 36-month-old children from the HR group were also observed in a longitudinal study by Yirmiya et al. (2006). At 24 months, the same group of children performed on average 2 standard deviations (SD) lower than a group of children with siblings with DS.

Some studies suggest that an atypical pattern of verbal development is already present in 12-monthold infants from the HR group (see Jones, Gliga, Bedford, Charman, \& Johnson, 2014; Ozonoff et al., 2014). In a study by Stone et al. (2007), children from the HR group aged between 12 and 23 months scored lower in tests measuring the understanding of words, phrases and use of gestures during interactions with parents. In one of their longitudinal studies, Paul et al. (2011) found that infants who showed symptoms of autism at 24 months had already scored lower on a scale measuring language expression in the $M u l-$ len Scales of Early Learning (MSEL, Mullen, 2005) at the age of 6 months. The project aimed at measuring early communication skills, such as cooing, laughing and pronouncing consonants. Characteristics associated with ASD can be already visible in early communication behaviours, which are a basis for the development of more complicated language skills (Jones et al., 2014).

However, differences in communication skills between HR and low-risk (LR) groups amongst children younger than 18 months, and especially younger than 12 months, have not been conclusively confirmed. Parents claim that their children from the HR group aged 18 months use fewer words than their peers, though these differences were not yet visible at 12 months (Mitchell et al., 2006; Zwaigenbaum et al., 2005). Landa and Garrett-Mayer (2006) as well as Ozonoff et al. (2014) found no differences in linguistic development between children from HR and LR groups at 6 months of age. In addition, no differences were found between 7- and 13-month-old children from these groups in terms of performance in tasks related to gaze following (Bedford et al., 2012). A study by Georgiades et al. (2013) revealed no deficits in the area of pragmatic language among 12-month-old infants.

Research on children aged 24 months is much more consistent. Most studies indicate the presence of deficits in communication in HR children (Landa \& Garrett-Mayer, 2006; Yirmiya et al., 2006; Zwaigenbaum et al., 2005). A study by Hudry et al. (2014) yielded some interesting data, where deficits in receptive skills observed in 14-month-old children from the HR group would only persist among the children diagnosed with ASD or another develop- mental disorder at 24 months. These results suggest that HR children follow a slightly different pattern of development, but difficulties that may show up early on can be aligned. However, Gamliel, Yirmiya, and Sigman (2007) concluded that although most of the earlier cognitive problems among HR children would disappear at 54 months, linguistic deficits both expressive and receptive - persisted.

Some difficulties in communication were also observed among older siblings (over 3 years of age) of children from the ASD group (for review: Cruz et al., 2013; Pisula \& Ziegart-Sadowska, in press). Difficulties occur in various aspects of communication: pragmatic use of language (Ben-Yizhak et al., 2011; Bolton et al., 1994; Folstein et al., 1999), syntax (Bishop, Maybery, Wong, Maley, \& Hallmayer, 2006), general language and communication skills (Gamliel et al., 2007; Levy \& Bar-Yuda, 2011). Bolton et al. (1994) reported a higher frequency of problems with reading and writing among relatives of individuals with autism as compared to the control group, as well as delays in linguistic development and problems with articulation.

Nevertheless, it is important to note that not all researchers agree about the presence of deficits related to language and communication among the siblings of individuals with ASD. Pilowsky, Yirmiya, Shalev, and Gross-Tsur (2003) found no differences in expressive linguistic skills between the siblings of children with autism and siblings of children with mental disabilities of unknown aetiology. Moreover, in their study children from the HR group scored higher than siblings of children with developmental language disorders. Folstein et al. (1999) reported that in comparison to parents of children with DS, significantly more parents of children with ASD displayed linguistic deficits and had problems with reading and spelling, yet siblings of children from the two groups did not differ significantly in terms of those abilities. Differences on the pragmatic skills scale were revealed only when a group of individuals who displayed linguistic difficulties in early childhood was selected from the relatives of children with ASD. Szatmari et al. (1993) found neither differences in the levels of development of communication and social skills nor in the history of language development in siblings of children with ASD, whereas BenYizhak et al. (2011) reported differences in pragmatic skills, but not reading.

As mentioned above, most of the research to date on BAP has focused on children from the HR group during infancy, and aged up to 3 years. A relatively small number of articles refer to older children, especially pre-schoolers, even though it is a period when a lot of important changes in the child's linguistic development take place. It is estimated that at the age of 2.50 a child knows and uses about 600 words, whereas at the age of 5-6 the number reaches about
Language abilities in siblings of children with ASD 
Ewa Pisula, Karolina Ziegart-Sadowska, Magdalena Kawa
15 thousand (Taylor, Christensen, Lawrence, Mitrou, \& Zubrick, 2013). An intensive period of development in the use of grammatical rules is observed around the age of 3 (Taylor et al., 2013). The number of words that a child can understand increases, as well as the ability to interpret their meaning within a context. There is an increase of proficiency and fluency in language use, formation of concepts and attribution of meanings to words. This dynamic development is also observed with regards to other cognitive skills that are important for communication - intense development of symbolic-play skills, memory skills and increase in curiosity. Four- and five-year-olds begin to understand that the actions of others cannot be predicted only by observation, but that one needs to take into account their desires and beliefs. It is therefore also an important period for the development of theory of mind (Saxe, Carey, $\&$ Kanwisher, 2004).

In the context of the above information, it seems important to investigate the functioning of pre-schoolers from the HR group in terms of the characteristics of BAP. Discovery of subtle developmental difficulties present among these children may facilitate the undertaking of suitable interventions aimed at supporting their development. The main goal of the current study was to test one of the elements of BAP - linguistic skills - among the children from the HR group. Typically developing children, whose siblings are diagnosed with ASD, were compared to peers whose siblings are affected with DS and children whose siblings develop typically. A group of correspondingly aged, high functioning (i.e. of normal IQ) children with ASD was additionally included in the study. The presented results are part of a larger project, which also aimed at measuring executive functions (inhibition, planning, working memory) and social skills (imitation, theory of mind). Only the information about language and communication skills will be presented here. The project is still under way, and the proclaimed analyses are of a preliminary character.

\section{PARTICIPANTS AND PROCEDURE}

\section{PARTICIPANTS}

Eighty-six intellectually normal children, aged between 4 years and 6 months and 6 years and 11 months, took part in the study (32 girls and 54 boys). They were divided into four groups: siblings of ASD children (S/ASD), high-functioning children with ASD (HF/ASD), siblings of children with DS (S/DS) and siblings of typically developing children (C - control children). Information about the numbers, ages and gender of children from the groups is presented in Table 1. None of the children, except for the HF/ASD group, were diagnosed with autism or any other developmental disorder.

In the HF/ASD group there were 4 girls and 24 boys. The group consisted of children diagnosed with autism, which is five times more common among boys than among girls (CDC, 2014). It can, therefore, be said that the test sample reflects the real distribution of genders in the population affected with ASD. The S/DS group was the smallest, mainly due to big difficulties in recruiting children who fulfilled the criteria (age 4 years and 6 months 6 years and 11 months, no diagnosis of developmental difficulties and siblings with DS) and whose parents gave consent for the child to take part in the study. It is typical to include children with other disorders (usually DS) in BAP research, because of the influence having a sibling with disability might have on the development of a child. This is why, despite the low numbers, the S/SD group was included in the analyses as a group brought up in a similar family environment, i.e. having a disabled sibling.

\section{PROCEDURE}

The project was approved by the Scientific Research Ethics Committee of the Faculty of Psychology the University of Warsaw (Poland). The children were recruited from therapeutic centres, inclusive and public

Table 1

Group size, gender and age characteristics

\begin{tabular}{lcccc}
\hline Group & S/ASD & HF/ASD & S/DS & C \\
\hline Number of children & $n=24$ & $n=28$ & $n=8$ & $n=26$ \\
\multirow{2}{*}{ Gender } & 11 girls; & 4 girls; & 4 girls; & 13 girls; \\
& 13 boys & 24 boys & 4 boys & 13 boys \\
& $4 ; 6-6 ; 10$ & $4 ; 7-6 ; 11$ & $4 ; 11-5 ; 9$ & $5 ; 1-6 ; 11$ \\
Age & $M=69.65$ & $M=68.46$ & $M=61.29$ & $M=71.12$ \\
& $S D=8.43$ & $S D=7.96$ & $S D=4.11$ & $S D=5.50$ \\
\hline
\end{tabular}


nurseries, and also through cooperation with intervention, associations and foundations. The investigated sample came from different parts of Poland, including the Warsaw metropolitan area, Częstochowa, Białystok and Łódź. The parents received written information about the study and in turn gave written consent for their children to take part in it.

\section{INSTRUMENTS}

The Vocabulary Test for Children (TSD) ${ }^{1}$ was used to examine communication and language skills (Psychological Test Laboratory of the Polish Psychological Association, 2013). The test is designed to assess verbal skills related to receptive language (passive) and expressive language (active), which are important indicators for the development of linguistic competence (Koć-Januchta, 2013). The overall TSD score allows one to assess the level of general linguistic competence of a child. Results on the RL (abbreviation from receptive language) subscale represent receptive language, the vocabulary that a child understands, even if he or she does not always use it. A high score on the RL subscale might be indirect evidence of a high capacity of working memory. Results on the EL (abbreviation from expressive language) subscale are indicative of the ability to retrieve from long-term memory, to activate and produce words describing given objects and the ability to complete sentences using appropriate words in the correct grammatical form. A high score on the EL scale is evidence of high competence in recalling and producing words from working memory as well as a practical knowledge of grammatical rules and the ability to apply them.

The test consists of 90 tasks, divided into four sub-tests. Subtests 1 and 3 assess receptive language, while subtests 2 and 4 assess expressive language. The content of the task and all instructions are read aloud to the child. There is no time limit for the test, but it usually takes about 20-30 minutes to complete. As a result we obtain scores for each of the subtests (S1, S2, S3, S4), as well on the two subscales, receptive language $(\mathrm{RL}=\mathrm{S} 1+\mathrm{S} 3)$ and expressive language $(\mathrm{EL}=\mathrm{S} 2+\mathrm{S} 4)$, and finally an overall score (OS).

Subtest 1, "Categories", consists of 6 sets of words, each of which is described by one keyword. The child has to assess whether a given word belongs to the category.

The subtest involves 6 thematic categories: clothes, body parts, animal names, offices, emotions and state symbols. In Subtest 2, "Pictures", the task is to name 26 stimuli presented in pictures. They can depict people, animals, things and food. Subtest 3, "Synonyms", requires the child to produce a synonym for a presented word (the child can choose from 3 possible answers). The subtest consists of 15 word-stimuli to choose synonyms for. Subtest 4, "Storytelling", involves a story that is read to the child. The story has 13 gaps, and the child needs to fill each gap with an appropriate word. The person reading the story pauses each time there is a gap; they can ask a leading question. The words produced by the child as an answer need to be in correct grammatical form.

The intelligence levels of the participants were controlled for using Raven's Coloured Progressive Matrices (CPM), adapted to Polish by Szustrowa and Jaworowska (2003).

\section{RESULTS}

Before making the between-group comparisons of communication and language skills, the groups were compared in terms of intellectual development (CPM results). Mean and standard deviations of the results of each group are presented in Table 2 .

The Kruskal-Wallis test for independent samples revealed differences in intelligence levels between the groups $(H=9.18, p=.037)$. Multiple pairwise comparisons revealed differences between S/ASD and $\mathrm{C}$ groups, HF/ASD and C, as well as S/DS and C. However, after the required level of significance was corrected for the number of comparisons, those differences turned out to be statistically insignificant.

The descriptive statistics of the analysed variables - indices calculated on the basis of the TSD test for S/ASD, HF/ASD, S/DS and C groups - are presented in Table 3.

The analysis of kurtosis and skewness of distribution parameters, histogram analysis and the Shapiro-Wilk and Kolmogorov-Smirnov tests revealed that the distribution of values of the S1, S2, S4 and EL variables deviates from the normal distribution in all of the investigated groups. Therefore further between-group analyses were carried out using the Kruskal-Wallis test for independent variables. Graphical representation of results obtained for each of the TSD subtests for S/ASD, HF/ASD, S/DS and C groups is presented in Figure 1. The statistics of the Kruskal-Wallis test for S1, S2, S3, S4, RL, EL and OS scores are presented in Table 4.

Table 2

Descriptive statistics of the results of Raven's Coloured Progressive Matrices test

\begin{tabular}{ccc}
\hline Group & $M$ & $S D$ \\
\hline S/ASD & 20.33 & 4.82 \\
HF/ASD & 21.21 & 4.74 \\
S/DS & 19.63 & 4.14 \\
C & 24.12 & 4.94 \\
\hline
\end{tabular}

Language abilities in siblings of children with $A S D$ 
Table 3

Descriptive statistics of the TDS test

\begin{tabular}{|c|c|c|c|c|c|c|}
\hline Variable & Group & $M$ & Me & $S D$ & $\min$ & $\max$ \\
\hline \multirow{5}{*}{ S1 } & S/ASD & 25.50 & 26.50 & 4.47 & 11 & 31 \\
\hline & $\mathrm{HF} / \mathrm{ASD}$ & 21.82 & 20.50 & 4.91 & 14 & 33 \\
\hline & S/DS & 24.13 & 13.84 & 3.72 & 19 & 29 \\
\hline & C & 25.19 & 25.50 & 4.99 & 14 & 34 \\
\hline & S/ASD & 16.21 & 17.00 & 4.42 & 5 & 23 \\
\hline \multirow{3}{*}{ S2 } & $\mathrm{HF} / \mathrm{ASD}$ & 14.00 & 13.50 & 4.36 & 5 & 24 \\
\hline & S/DS & 16.25 & 15.50 & 2.44 & 14 & 20 \\
\hline & $\mathrm{C}$ & 17.27 & 18.00 & 5.39 & 0 & 24 \\
\hline \multirow{5}{*}{ S3 } & S/ASD & 8.33 & 9.00 & 3.69 & 0 & 15 \\
\hline & $\mathrm{HF} / \mathrm{ASD}$ & 6.50 & 6.50 & 2.78 & 1 & 13 \\
\hline & S/DS & 8.88 & 10.00 & 3.09 & 4 & 12 \\
\hline & $\mathrm{C}$ & 9.54 & 10.00 & 3.61 & 3 & 15 \\
\hline & S/ASD & 7.17 & 7.00 & 2.73 & 0 & 11 \\
\hline \multirow{3}{*}{ S4 } & $\mathrm{HF} / \mathrm{ASD}$ & 6.50 & 6.50 & 3.06 & 1 & 12 \\
\hline & $\mathrm{S} / \mathrm{DS}$ & 7.75 & 8.00 & 1.58 & 5 & 10 \\
\hline & C & 8.31 & 9.00 & 2.33 & 3 & 13 \\
\hline \multirow{5}{*}{$\mathrm{RL}$} & S/ASD & 33.83 & 34.50 & 7.45 & 11 & 46 \\
\hline & $\mathrm{HF} / \mathrm{ASD}$ & 28.32 & 28.00 & 7.00 & 15 & 42 \\
\hline & S/DS & 33.00 & 32.00 & 5.71 & 24 & 40 \\
\hline & $\mathrm{C}$ & 34.73 & 34.00 & 7.60 & 23 & 46 \\
\hline & S/ASD & 23.38 & 24.50 & 6.39 & 5 & 33 \\
\hline \multirow{2}{*}{ EL } & $\mathrm{HF} / \mathrm{ASD}$ & 20.50 & 21.00 & 6.65 & 8 & 34 \\
\hline & S/DS & 24.00 & 23.50 & 3.30 & 19 & 29 \\
\hline \multirow{5}{*}{ OS } & $\mathrm{C}$ & 25.58 & 28.00 & 7.00 & 6 & 35 \\
\hline & S/ASD & 57.21 & 61.00 & 12.69 & 24 & 79 \\
\hline & $\mathrm{HF} / \mathrm{ASD}$ & 48.82 & 46.00 & 12.60 & 23 & 76 \\
\hline & S/DS & 57.00 & 54.50 & 7.52 & 48 & 69 \\
\hline & C & 60.31 & 60.50 & 13.41 & 37 & 81 \\
\hline
\end{tabular}

Note. $\mathrm{RL}$ - receptive language $(\mathrm{S} 1+\mathrm{S} 3), \mathrm{EL}$ - expressive language $(\mathrm{S} 2+\mathrm{S} 4), \mathrm{OS}$ - overall score $(\mathrm{S} 1+\mathrm{S} 2+\mathrm{S} 3+\mathrm{S} 4), \mathrm{S} 1, \mathrm{~S} 2, \mathrm{~S} 3, \mathrm{~S} 4-$ TDS subtest 1, 2, 3, 4

As shown in Table 4, differences between groups occurred in all of the TSD sub-tests, except for S4. Multiple pairwise comparisons were used in order to assess which groups differed from one another (Table 5).

Significant differences between high functioning children diagnosed with autism (HF/ASD) and typically developing siblings of children with DS as well as siblings of typically developing children (S/DS and C) were revealed for the results of subtest 1 (S1 variable). In all of the cases, the children from the HF/ASD group scored lower than the remaining groups. Addi- tionally, HF/ASD children scored lower than C children on the S2 and S3 subtests. Differences were found for the sums of S1 and S3 scores (RL variable) between the HF/ASD and the $\mathrm{C}$ as well as S/ASD groups (differences were observed in the same direction as in the previously listed comparisons). Children from the HF/ ASD group significantly differed from the children from the $\mathrm{C}$ group in terms of the overall score (OS) for the TSD test, as well as the sum of scores for S2 and S4 (EL variable). No differences were observed between the scores obtained by groups for the S4 subtest. 

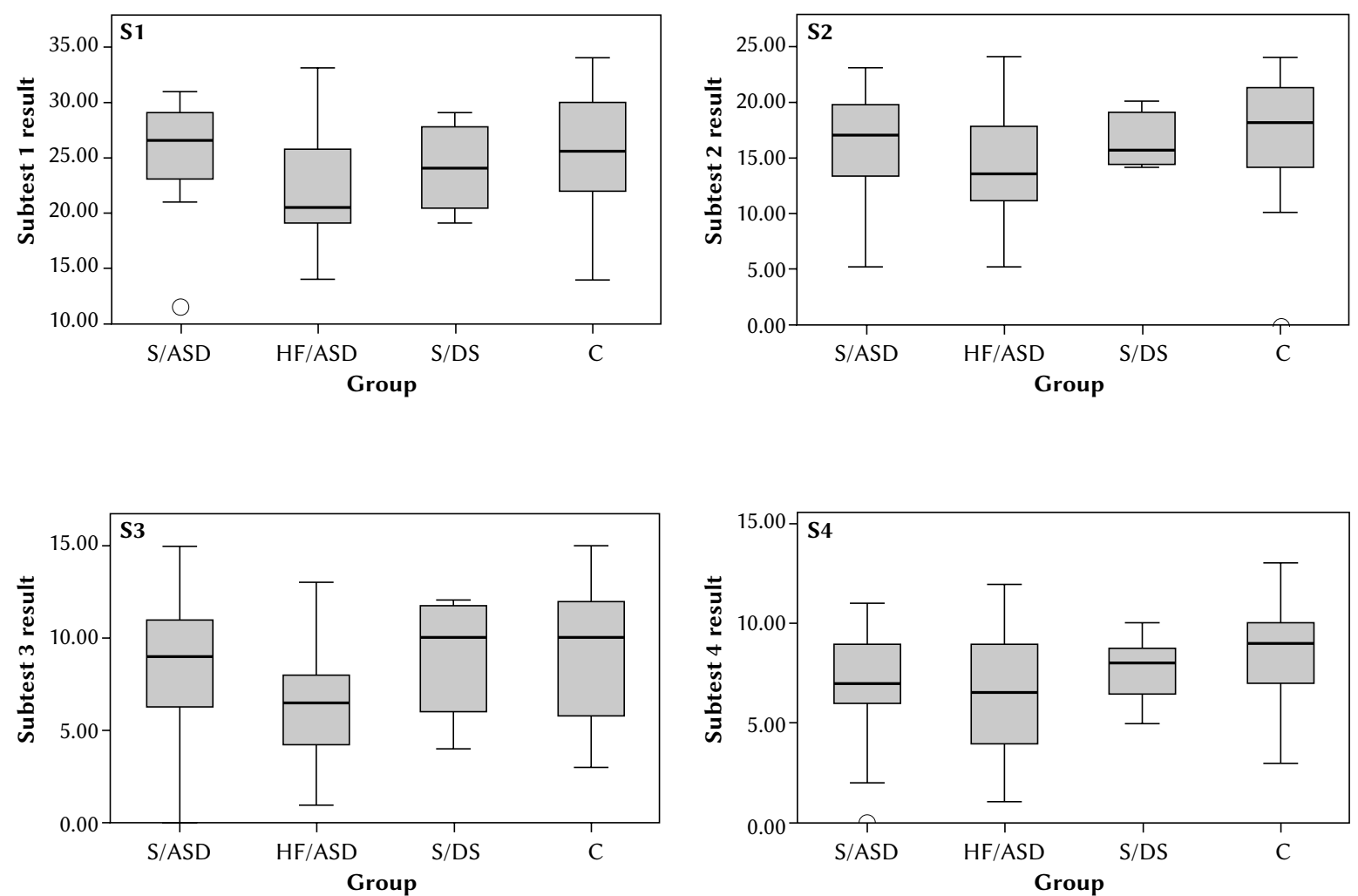

Language abilities in siblings of children with ASD
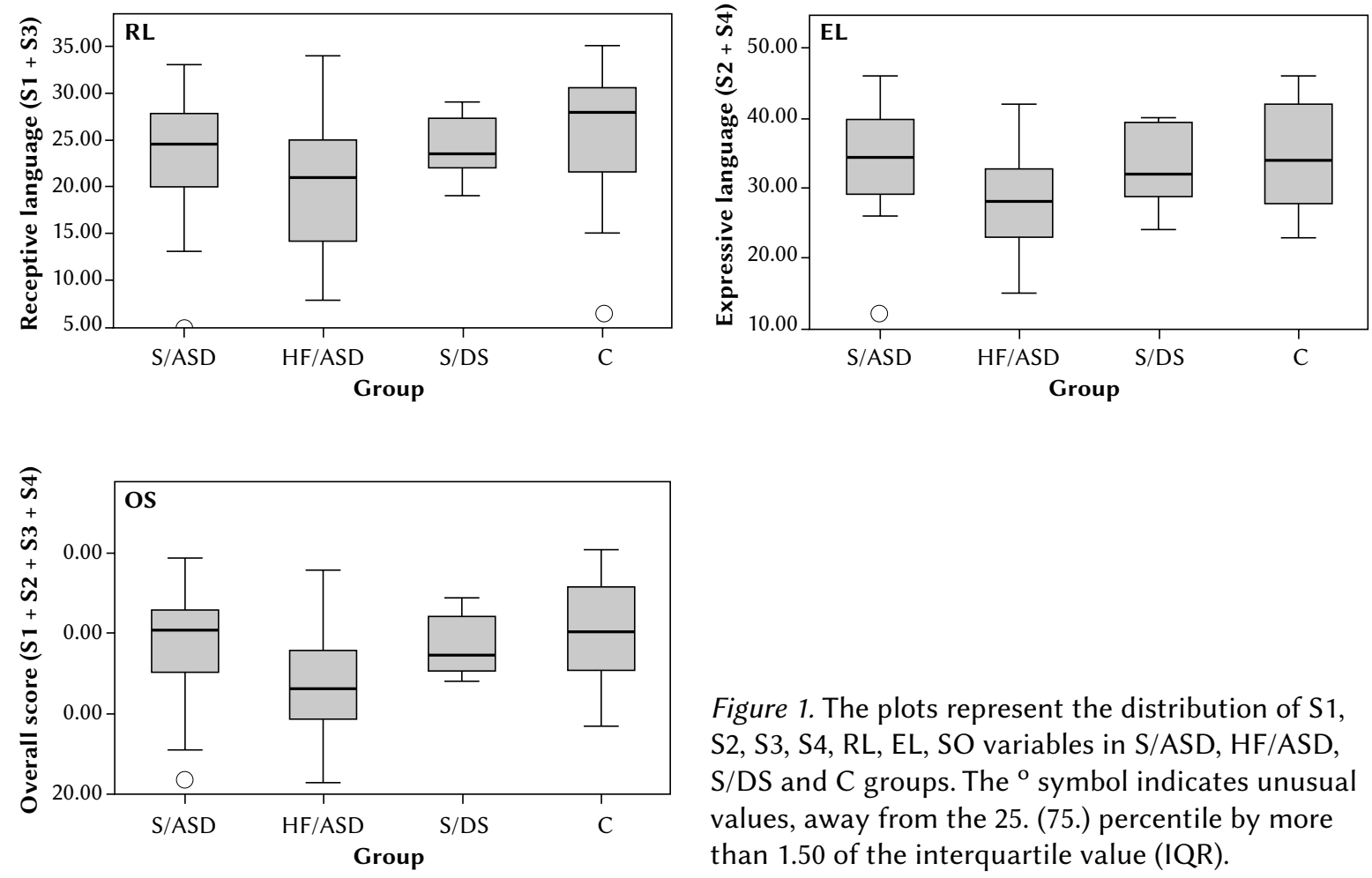

Figure 1. The plots represent the distribution of $\mathrm{S} 1$, S2, S3, S4, RL, EL, SO variables in S/ASD, HF/ASD, $\mathrm{S} / \mathrm{DS}$ and $\mathrm{C}$ groups. The ${ }^{\circ}$ symbol indicates unusual values, away from the 25. (75.) percentile by more than 1.50 of the interquartile value (IQR).

An analysis of individual overall TSD scores for each of the participants was also performed. Children whose overall score was 2 SD below the manual average for the given age were then selected. The analysis was carried out on results previously re-cal- culated to sten scores (average $=5.50, S D=2.00$ ). Among all of the subjects, only two children in the HF/ASD group fulfilled that criterion. No scores below the manual average were noted in the remaining groups. 
Table 4

Comparison of distributions of S1, S2, S3, S4, RL, EL and OS variables in the S/ASD, HF/ASD, S/DS and $C$ groups (results of the Kruskal-Wallis test for independent variables; $N=86$ )

\begin{tabular}{ccccc}
\hline Group & Variables & $H$ & $d f$ & $p$ \\
\hline S/ASD & S1 & 10.69 & 3 & $\mathbf{0 1 4}$ \\
$(n=24)$ & S2 & 8.95 & 3 & $\mathbf{0 3 0}$ \\
HF/ASD & S3 & 11.07 & 3 & $\mathbf{0 1 1}$ \\
$(n=28)$ & S4 & 5.93 & 3 & .115 \\
S/DS $(n=8)$ & RL & 12.01 & 3 & $\mathbf{0 0 7}$ \\
C $(n=26)$ & EL & 9.10 & 3 & $\mathbf{0 2 8}$ \\
& OS & 10.24 & 3 & $\mathbf{0 1 7}$ \\
\hline
\end{tabular}

Note. $n$ - sample size, $d f$ - degrees of freedom, $p$ - significance level. Statistically significant $(p<.05)$ results in bold.

Table 5

Multiple pairwise comparisons for S1, S2, S3, S4, RL, EL and OS variables. Only statistically significant $(p<.05)$ results are presented

\begin{tabular}{|c|c|c|c|c|c|c|}
\hline Variables & $\begin{array}{c}\text { Group } 1 \\
\text { (Mean rank) }\end{array}$ & vs. & $\begin{array}{c}\text { Group } 2 \\
\text { (Mean rank) }\end{array}$ & Test statistic & $S D$ & Significance \\
\hline \multirow[b]{2}{*}{$\mathrm{S} 1$} & HF/ASD (31.34) & vs. & C (49.38) & -18.05 & 6.79 & .047 \\
\hline & HF/ASD (31.34) & vs. & S/ASD (51.63) & 20.29 & 6.93 & .021 \\
\hline $\mathrm{S} 2$ & HF/ASD (32.68) & vs. & $C(52.52)$ & -19.84 & 6.78 & .021 \\
\hline S3 & HF/ASD (31.43) & vs. & $C(53.10)$ & -21.67 & 6.78 & .008 \\
\hline \multirow{2}{*}{$R L$} & $\mathrm{HF} / \mathrm{ASD}(30.23)$ & vs. & S/ASD (49.54) & 19.31 & 6.94 & .032 \\
\hline & HF/ASD (30.23) & vs. & $C(51.35)$ & -21.11 & 6.79 & .011 \\
\hline EL & HF/ASD (33.09) & vs. & $C(53.48)$ & -20.39 & 6.79 & .016 \\
\hline OS & HF/ASD (31.38) & vs. & $C(51.67)$ & -20.30 & 6.80 & .017 \\
\hline
\end{tabular}

Finally, it was verified whether there was a correlation between age and level of linguistic skills (TSD overall score) for all of the subjects together. The Pearson correlation analysis revealed that such a relationship exists $(r=.48, p<.001)$.

\section{DISCUSSION}

Language and communication deficits are among the most important characteristics of autism spectrum disorders. They are of a broad and diverse nature that includes both verbal and non-verbal communication (Tager-Flusberg, Paul, \& Lord, 2005). Many researchers confirm that difficulties in these areas are also present among the relatives of individuals with by autism. These can be related to: the practical use of language (Ben-Yizhak et al., 2011; Bolton et al., 1994; Bishop et al., 2004; Landa et al., 1992; Losh, Childres, Lam, \& Piven, 2008; Folstein et al., 1999; Ruser et al., 2007), syntax (Bishop et al., 2006), reading and understanding (Piven \& Palmer, 1997), as well as general communication skills (Bishop et al., 2004; Ruser et al., 2007; Wheelwright, Auyeung, Allison, \& Baron-Cohen, 2010; Whitehouse, Barry, $\&$ Bishop, 2007). However, research is not conclusive, and some studies do not confirm the existence of language or communication deficits among the relatives of individuals with ASD (Folstein et al., 1999; Pilowsky et al., 2003; Schmidt et al., 2008).

It should be stressed that most of the research is concerned either with infants and children of up to 
3 years of age or individuals in a broad spectrum of ages. Very little of the available data relates solely to pre-schoolers. The hereby presented study is an attempt to verify the levels of language and communication skills among pre-schoolers, in particular siblings of individuals diagnosed with ASD. Children aged 4 years and 6 months -6 years and 11 months took part in the study. This age group was chosen due, in part, to the dynamic nature of the development of language competence in this period of childhood and also due to the low number of publications concerned with $\mathrm{BAP}$ in this age range. We analysed receptive language as well as expressive language. Both of these areas are crucial to effective communication using language, and thus the proper decoding and generation of information (Koć-Januchta, 2013). The overall levels of linguistic skills that consist of receptive language and expressive language were also assessed. The controls involved groups of children who have siblings with DS as well as children whose siblings develop typically. In order to complete the spectrum of potential differences a group of high functioning children with autism was also included.

The results suggest an absence of differences in terms of both expressive language and receptive language between the siblings of ASD children and the siblings of children with DS or typically developing children. In terms of receptive language (which includes known vocabulary) as well as in terms of the overall communication skills, siblings of children with ASD scored higher than high functioning children with autism. The latter group differed significantly from the remaining groups in terms of skills associated with expressive language, receptive language and in overall levels of language and communication competences. The results are in line with current knowledge about the linguistic functioning of children with autism spectrum disorders (Elsabbagh \& Johnson, 2007; Lai, Lombardo, \& Baron-Cohen, 2014; Levy, Mandell, \& Schultz, 2009).

Summing up this part of the study, one can conclude that, in light of the results, pre-school siblings of children with autism do not exhibit significant deficits in the area of the measured communication and language skills. Characteristics of broader autism phenotype related to the area of the assessed skills were not observed in this group.

The presented results correspond to some of the previous research on communication and language skills among siblings of children with autism. One example of this is the data gathered by Szatmari et al. (1993), who did not observe differences in communication and social skills among siblings of children with ASD. Folstein et al. (1999) also did not find significant discrepancies in terms of language skills (including reading, spelling and pragmatic use of language) between siblings of children with ASD and siblings of children with DS. A study by Pilowsky et al. (2003) revealed similar levels of language skills among siblings of children with ASD and siblings of children with intellectual disabilities of unknown aetiology. In another publication, these researchers likewise reported similar levels of neurocognitive functioning in these groups (Pilowsky, Yirmiya, Gross-Tsur, \& Shalev, 2007). However, it needs to be added that whereas Ben-Yizhak et al. (2011) reported no differences between the siblings of pre-school children with ASD and the control group in terms of ability to read and school achievements, they did observe difficulties with pragmatic use of language among siblings of children with ASD.

Nevertheless, a body of research has confirmed the occurrence of communication and language deficits among siblings of individuals with ASD. Gamliel, Yirmiya, Jaffe, Manor, and Sigman (2009) indicated that $40 \%$ of siblings of children with ASD aged 7 have linguistic and cognitive problems. The team of Chuthapisith (2007) observed delays in linguistic development in some siblings of children with ASD. Additionally, Bishop et al. (2006) reported that such children have difficulties with syntax. There are data indicating deficits in fluency of speech in that group (Hughes, Plumet, \& Leboyer, 1999), problems with reading and spelling (Fombonne, Bolton, Prior, Jordan, \& Rutter, 1997) and lower overall levels of communication skills (Bolton et al., 1994).

The discrepancies in the results of research to date might be due to the fact that BAP is present only in a fraction of relatives of individuals with ASD (Gerdts \& Bernier, 2011). If the sample size is small (as in the present study), such people might not be included. The ability to discriminate between subgroups of relatives of individuals with ASD exhibiting features of BAP (BAP+) and those with no such symptoms (BAP-) would allow for a better assessment of language skills in the $\mathrm{BAP}+$ group, especially interesting in the context of research on the genetics of autism. However, it cannot be ruled out that with regard to the variables assessed among pre-school children from the HR group such difficulties do not occur and they do not comprise (at that age) an element of BAP.

The current study revealed a correlation between the age of the examined children (ranging between 4 years and 6 months and 6 years and 11 months) and their language skills. The correlation calculated for the entire sample was moderately strong $(r=.48)$. It seems necessary to include the age of subjects in further analyses. The pre-school period is a time of important developmental changes, which might be characterised by a different dynamic in children from the ASD risk group than in children from families bearing no such risk. The age range of children included in this study was quite broad, which might have hindered the collection of more valuable information.
Language abilities in siblings of children with $A S D$ 


\section{CONCLUSIONS}

The current study supports the view that there are no differences in language and communication skills among siblings of children with ASD. It is however important to stress that the small number of children in each group was a significant limitation for this project and the sample is not representative of the population. The presented results, therefore, need to be interpreted with caution and treated as preliminary data only.

Ewa Pisula, Karolina Ziegart-Sadowska, Magdalena Kawa Relating the presented variables to other elements of functioning of children whose siblings are affected with ASD may complement the presented information about the development of this group of children.

\section{ACKNOWLEDGMENTS}

The authors would like express special gratitude to JiM Foundation from Łódź for facilitating contact with families involved in the study, as well as to the Private Inclusive Nursery "Zielony Latawiec" in Warsaw, the Early Intervention Centre of the Polish Society for Mentally Disabled Individuals in Warsaw, Autonomous Inclusive Nursery no. 41 in Białystok, Private Therapeutic Nursery "Przyjazny Domek" in Białystok, Inclusive Nursery no. 314 in Warsaw and Dr. Anna Banasiak and Mr. Tomasz Mroz, MA. We would also like to thank Ms Maja Niedzielska, Ms Monika Hodyra, Ms Marta Czerny and Ms Marta Gruhn for help with collecting data.

This paper was funded by the project of the National Science Center in Poland, \#DEC-2011/03/B/HS6/03326.

\section{ENDNOTES}

1 Abbreviation from the original name in Polish: Test Słownikowy dla Dzieci.

\section{RefERENCES}

American Psychiatric Association (2013). Diagnostic and Statistical Manual of Mental Disorders ( $5^{\text {th }}$ ed.). Arlington: American Psychiatric Publishing.

Bedford, R., Elsabbagh, M., Gliga, T., Pickles, A., Senju, A., Charman, T., \& BASIS team. (2012). Precursors to social and communication difficulties in infants at-risk for autism: gaze following and attentional engagement. Journal of Autism and Developmental Disorders, 42, 2208-2218.

Ben-Yizhak, N., Yirmiya, N., Seidman, I., Alon, R., Lord, C., \& Sigman, M. (2011). Pragmatic language and school related linguistic abilities in siblings of children with autism. Journal of Autism and Developmental Disorders, 41, 750-760.
Bishop, D. V. M., Maybery, M., Maley, A., Wong, D., Hill, W., \& Hallmayer, J. (2004). Using self-report to identify the broad phenotype in parents of children with autistic spectrum disorders: a study using the Autism-Spectrum Quotient. Journal of Child Psychology and Psychiatry, and Allied Disciplines, 45, 1431-1436.

Bishop, D. V. M., Maybery, M., Wong, D., Maley, A., \& Hallmayer, J. (2006). Characteristics of the broader phenotype in autism: a study of siblings using the children's communication checklist-2. American Journal of Medical Genetics. Part B, Neuropsychiatric Genetics: The Official Publication of the International Society of Psychiatric Genetics, 141B, 117-122.

Bolton, P., Macdonald,H.,Pickles, A., Rios, P., Goode, S., Crowson, M., \& Rutter, M. (1994). A case-control family history study of autism. Journal of Child Psychology and Psychiatry, and Allied Disciplines, 35, 877-900.

Cassel, T. D., Messinger, D. S., Ibanez, L. V., Haltigan, J. D., Acosta, S. I., \& Buchman, A. C. (2007). Early social and emotional communication in the infant siblings of children with autism spectrum disorders: an examination of the broad phenotype. Journal of Autism and Developmental Disorders, 37, 122-132.

CDC. Prevalence of Autism Spectrum Disorder Among Children Aged 8 Years - Autism and Developmental Disabilities. Monitoring Network, 11 Sites, United States, 2010. Surveillance Summaries, March 28, 2014; 63 (SS02): 1-21.

Chuthapisith, J., Ruangdaraganon, N., Sombuntham, T., \& Roongpraiwan, R. (2007). Language development among the siblings of children with autistic spectrum disorder. Autism: The International Journal of Research and Practice, 11, 149-160.

Constantino, J. N., Lajonchere, C., Lutz, M., Gray, T., Abbacchi, A., McKenna, K., \& Todd, R. D. (2006). Autistic social impairment in the siblings of children with pervasive developmental disorders. The American Journal of Psychiatry, 163, 294-296. DOI: 10.1176/appi.ajp.163.2.294.

Cruz, L. P., Camargos-Junior, W., Rocha, F. L., Cruz, L. P., Camargos-Junior, W., \& Rocha, F. L. (2013). The broad autism phenotype in parents of individuals with autism: a systematic review of the literature. Trends in Psychiatry and Psychotherapy, 35, 252-263.

Currenti, S. A. (2010). Understanding and determining the etiology of autism. Cellular and Molecular Neurobiology, 30, 161-171.

Dawson, G., Webb, S., Schellenberg, G. D., Dager, S., Friedman, S., Aylward, E., \& Richards, T. (2002). Defining the broader phenotype of autism: genetic, brain, and behavioral perspectives. Development and Psychopathology, 14, 581-611. 
Dodds, L., Fell, D. B., Shea, S., Armson, B. A., Allen, A. C., \& Bryson, S. (2011). The role of prenatal, obstetric and neonatal factors in the development of autism. Journal of Autism and Developmental Disorders, 41, 891-902.

Elsabbagh, M., \& Johnson, M. H. (2007). Infancy and autism: progress, prospects, and challenges. Progress in Brain Research, 164, 355-383.

Folstein, S. E., Santangelo, S. L., Gilman, S. E., Piven, J., Landa, R., Lainhart, J., \& Wzorek, M. (1999). Predictors of cognitive test patterns in autism families. Journal of Child Psychology and Psychiatry, and Allied Disciplines, 40, 1117-1128.

Fombonne, E., Bolton, P., Prior, J., Jordan, H., \& Rutter, M. (1997). A family study of autism: cognitive patterns and levels in parents and siblings. Journal of Child Psychology and Psychiatry, and Allied Disciplines, 38, 667-683.

Gamliel, I., Yirmiya, N., \& Sigman, M. (2007). The development of young siblings of children with autism from 4 to 54 months. Journal of Autism and Developmental Disorders, 37, 171-183.

Gamliel, I., Yirmiya, N., Jaffe, D. H., Manor, O., \& Sigman, M. (2009). Developmental trajectories in siblings of children with autism: cognition and language from 4 months to 7 years. Journal of Autism and Developmental Disorders, 39, 1131-1144.

Georgiades, S., Szatmari, P., Zwaigenbaum, L., Bryson, S., Brian, J., Roberts, W., \& Garon, N. (2013). A prospective study of autistic-like traits in unaffected siblings of probands with autism spectrum disorder. JAMA Psychiatry, 70, 42-48.

Gerdts, J., \& Bernier, R. (2011). The broader autism phenotype and its implications on the etiology and treatment of autism spectrum disorders. Autism Research and Treatment, 2011, e545901.

Goldberg, W. A., Jarvis, K. L., Osann, K., Laulhere, T. M., Straub, C., Thomas, E., \& Spence, M. A. (2005). Brief report: early social communication behaviors in the younger siblings of children with autism. Journal of Autism and Developmental Disorders, 35, 657-664.

Hudry, K., Chandler, S., Bedford, R., Pasco, G., Gliga, T., Elsabbagh, M., Johnson, M. H., \& Charman, T. (2014). Early language profiles in infants at highrisk for autism spectrum disorders. Journal of $A u$ tism and Developmental Disorders, 44, 154-167.

Hughes, C., Plumet, M. H., \& Leboyer, M. (1999). Towards a cognitive phenotype for autism: increased prevalence of executive dysfunction and superior spatial span amongst siblings of children with autism. Journal of Child Psychology and Psychiatry, and Allied Disciplines, 40, 705-718.

Iverson, J. M., \& Wozniak, R. H. (2007). Variation in vocal-motor development in infant siblings of children with autism. Journal of Autism and Developmental Disorders, 37, 158-170.
Jones, E. J. H., Gliga, T., Bedford, R., Charman, T., \& Johnson, M. H. (2014). Developmental pathways to autism: A review of prospective studies of infants at risk. Neuroscience \& Biobehavioral Reviews, 39, 1-33.

Koć-Januchta, M. (2013). Test Stownikowy dla Dzieci. Podręcznik [Vocabulary Test for Children. Textbook]. Warsaw: Pracownia Testów Psychologicznych Polskiego Towarzystwa Psychologicznego.

Lai, M.-C., Lombardo, M. V., \& Baron-Cohen, S. (2014). Autism. Lancet, 383, 896-910.

Landa, R., \& Garrett-Mayer, E. (2006). Development in infants with autism spectrum disorders: a prospective study. Journal of Child Psychology and Psychiatry, and Allied Disciplines, 47, 629-638.

Landa, R., Piven, J., Wzorek, M. M., Gayle, J. O., Chase, G. A., \& Folstein, S. E. (1992). Social language use in parents of autistic individuals. Psychological Medicine, 22, 245-254.

Levy, S. E., Mandell, D. S., \& Schultz, R. T. (2009). Autism. Lancet, 374, 1627-1638.

Levy, Y., \& Bar-Yuda, C. (2011). Language performance in siblings of nonverbal children with. $A u-$ tism, 15, 341-354.

Losh, M., Childress, D., Lam, K., \& Piven, J. (2008). Defining key features of the broad autism phenotype. American Journal of Medical Genetics. Part B, Neuropsychiatric Genetics: The Official Publication of the International Society of Psychiatric Genetics, 147B, 424-433.

Mitchell, S., Brian, J., Zwaigenbaum, L., Roberts, W., Szatmari, P., Smith, I., \& Bryson, S. (2006). Early language and communication development of infants later diagnosed with autism spectrum disorder. Journal of Developmental and Behavioral Pediatrics: JDBP, 27 (2 Suppl): S69-78.

Mullen, E. (1995). Mullen Scales of Early Learning. Circle Pines, MN: American Guidance Service Inc. Mundy, P., Hogan, A., \& Doehring, P. (1996). A Preliminary Manual for the Abridged Early Social Communication Scales (ESCS). Unpublished textbook. University of Miami.

Ozonoff, S., Young, G. S., Belding, A., Hill, M., Hill, A., Hutman, T., \& losif, A.-M. (2014). The broader autism phenotype in infancy: when does it emerge? Journal of the American Academy of Child and Adolescent Psychiatry, 53, 398-407.

Paul, R., Fuerst, Y., Ramsay, G., Chawarska, K., \& Klin, A. (2011). Out of the mouths of babes: Vocal production in infant siblings of children with ASD. Journal of Child Psychology and Psychiatry, 52, 588-598.

Pilowsky, T., Yirmiya, N., Gross-Tsur, V., \& Shalev, R. S. (2007). Neuropsychological functioning of siblings of children with autism, siblings of children with developmental language delay, and siblings of children with mental retardation of unknown
Language abilities in siblings of children with ASD 
Ewa Pisula,

Karolina Ziegart-Sadowska, Magdalena Kawa genetic etiology. Journal of Autism and Developmental Disorders, 37, 537-552.

Pilowsky, T., Yirmiya, N., Shalev, R. S., \& Gross-Tsur, V. (2003). Language abilities of siblings of children with autism. Journal of Child Psychology and Psychiatry, and Allied Disciplines, 44, 914-925.

Pisula, E., \& Ziegart-Sadowska, K. (in press). Social Communication and Language Deficits in Parents and Siblings of Children with ASD - a Short Review. In: M. Fitzgerald (ed.), Autism. Rijeka: InTech.

Piven, J., \& Palmer, P. (1997). Cognitive deficits in parents from multiple-incidence autism families. Journal of Child Psychology and Psychiatry, and Allied Disciplines, 38, 1011-1021.

Ruser, T. F., Arin, D., Dowd, M., Putnam, S., Winklosky, B., Rosen-Sheidley, B., \& Folstein, S. (2007). Communicative competence in parents of children with autism and parents of children with specific language impairment. Journal of Autism and Developmental Disorders, 37, 1323-1336.

Saxe, R., Carey, S., \& Kanwisher, N. (2004). Understanding other minds: linking developmental psychology and functional neuroimaging. Annual Review of Psychology, 55, 87-124.

Schmidt, G. L., Kimel, L. K., Winterrowd, E., Pennington, B. F., Hepburn, S. L., \& Rojas, D. C. (2008). Impairments in phonological processing and nonverbal intellectual function in parents of children with autism. Journal of Clinical and Experimental Neuropsychology, 30, 557-567.

Stone, W. L., McMahon, C. R., Yoder, P. J., \& Walden, T. A. (2007). Early social-communicative and cognitive development of younger siblings of children with autism spectrum disorders. Archives of Pediatrics \& Adolescent Medicine, 161, 384-390.

Sucksmith, E., Roth, I., \& Hoekstra, R. A. (2011). Autistic traits below the clinical threshold: re-examining the broader autism phenotype in the $21^{\text {st }}$ century. Neuropsychology Review, 21, 360-389.

Szatmari, P., Jones, M. B., Tuff, L., Bartolucci, G., Fisman, S., \& Mahoney, W. (1993). Lack of cognitive impairment in first-degree relatives of children with pervasive developmental disorders. Journal of the American Academy of Child and Adolescent Psychiatry, 32, 1264-1273.

Szustrowa, T., \& Jaworowska, A. (2003). Test Matryc Ravena w Wersji Kolorowej [Raven's Coloured Progressive Matrices Test]. Warsaw: Pracownia Testów Psychologicznych PTP.

Tager-Flusberg, H., Paul, R., \& Lord, C. (2005). Communication in autism. In: F. Volkmar, A. Klin, R. Paul, \& D. Cohen (eds.), Handbook of Autism and Pervasive Developmental Disorders ( $3^{\text {rd }}$ ed., pp. 335-364). Hoboken, N.Y.: Wiley \& Sons.

Taylor, C. L., Christensen, D., Lawrence, D., Mitrou, F., \& Zubrick, S. R. (2013). Risk factors for children's receptive vocabulary development from four to eight years in the longitudinal study of Australian children. PLoS One, 8, e73046.

Toth, K., Dawson, G., Meltzoff, A. N., Greenson, J., \& Fein, D. (2007). Early Social, Imitation, Play, and Language Abilities of Young Non-Autistic Siblings of Children with Autism. Journal of Autism and Developmental Disorders, 37, 145-157.

Wheelwright, S., Auyeung, B., Allison, C., \& BaronCohen, S. (2010). Defining the broader, medium and narrow autism phenotype among parents using the Autism Spectrum Quotient (AQ). Molecular Autism, 1, 10.

Whitehouse, A. J. O., Barry, J. G., \& Bishop, D. V. M. (2007). The broader language phenotype of autism: a comparison with specific language impairment. Journal of Child Psychology and Psychiatry, and Allied Disciplines, 48, 822-830.

World Health Organization. (2002). Manual of the International Statistical Classification of the Diseases and Related Health Problems (10 $10^{\text {th }}$ ed., t. 1). Genewa: World Health Organization.

Yirmiya, N., Gamliel, I., Pilowsky, T., Feldman, R., Baron-Cohen, S., \& Sigman, M. (2006). The development of siblings of children with autism at 4 and 14 months: social engagement, communication, and cognition. Journal of Child Psychology and Psychiatry, and Allied Disciplines, 47, 511-523.

Zespół Pracowni Testów Psychologicznych Polskiego Towarzystwa Psychologicznego [Association of Psychological Tests Laboratories of Polish Psychoogical Society] (2013). Test Stownikowy dla Dzieci [Vocabulary Test for Children]. Warsaw: Pracownia Testów Psychologicznych Polskiego Towarzystwa Psychologicznego.

Zwaigenbaum, L., Bryson, S., Rogers, T., Roberts, W., Brian, J., \& Szatmari, P. (2005). Behavioral manifestations of autism in the first year of life. International Journal of Developmental Neuroscience, 23, 143-152. 